\title{
Photocatalytic degradation and photo-Fenton oxidation of Congo red dye pollutants in water using natural chromite-response surface optimization
}

\author{
Mohamed Shaban ${ }^{1} \cdot$ Mostafa R. Abukhadra ${ }^{1,2}$ - Suzan S. Ibrahim ${ }^{3}$. \\ Mohamed .G. Shahien ${ }^{2}$
}

Received: 8 July 2017/ Accepted: 25 October 2017/Published online: 4 November 2017

(c) The Author(s) 2017. This article is an open access publication

\begin{abstract}
Refined natural Fe-chromite was characterized by XRD, FT-IR, reflected polarized microscope, XRF and UV spectrophotometer. Photocatalytic degradation and photo-Fenton oxidation of Congo red dye by Fe-chromite was investigated using $1 \mathrm{~mL} \mathrm{H}_{2} \mathrm{O}_{2}$. The degradation of dye was studied as a function of illumination time, chromite mass, initial dye concentration, and $\mathrm{pH}$. Fe-chromite acts as binary oxide system from chromium oxide and ferrous oxide. Thus, it exhibits photocatalytic properties under UV illumination and photo-Fenton oxidation after addition of $\mathrm{H}_{2} \mathrm{O}_{2}$. The degradation in the presence of $\mathrm{H}_{2} \mathrm{O}_{2}$ reached the equilibrium stage after $8 \mathrm{~h}(59.4 \%)$ but in the absence of $\mathrm{H}_{2} \mathrm{O}_{2}$ continued to $12 \mathrm{~h}(54.6 \%)$. Photocatalytic degradation results fitted well with zero, first order and second order kinetic model but it represented by second order rather than by the other models. While the photo-Fenton oxidation show medium fitting with the second order kinetic model only. The values of kinetic rate constants for the photo-Fenton oxidation were greater than those for the photocatalytic degradation. Thus, degradation of Congo red dye using chromite as catalyst is more efficient by photo-Fenton oxidation. Based on the response surface
\end{abstract}

Mostafa R. Abukhadra

Abukhadra89@Science.bsu.edu.eg

1 Nanophotonics and Applications Lab, Physics Department, Faculty of Science, Beni-Suef University, Beni Suef 62514, Egypt

2 Geology Department, Faculty of Science, Beni-Suef University, Beni Suef, Egypt

3 Central Metallurgical Research and Development Institute (CMRDI), Helwan, 11421 Cairo, Egypt analysis, the predicted optimal conditions for maximum removal of Congo red dye by photocatalytic degradation $(100 \%)$ were $12 \mathrm{mg} / \mathrm{l}, 0.14 \mathrm{~g}, 3$, and $11 \mathrm{~h}$ for dye concentration, chromite mass, $\mathrm{pH}$, and illumination time, respectively. Moreover, the optimum condition for photoFenton oxidation of dye (100\%) is $13.5 \mathrm{mg} / \mathrm{l}, 0.10 \mathrm{~g}$, 4, and $10 \mathrm{~h}$, respectively.

Keywords Chromite - Binary oxide - Congo red dye · Photocatalysis · Photo-Fenton oxidation

\section{Introduction}

Rapid urbanization, industrialization and economic development in recent years lead to a continuous influx of toxic materials such as heavy metals, dyes, and pesticides into a water body which frequently causes water pollution (Shaban et al. 2017a). Water pollution became one of the biggest environmental problems all over the world. It is usually hazardous to human populations and the environment (Seliem et al. 2016). Therefore, the removal of water contaminants is critical demand in the contemporary world.

Dyes are aromatic compounds used for coloring applications (Ibrahim and Sani 2010). Dyes are widely used in several modern industries such as textile, leather, paper, printing, paint, pigments, rubber and plastic. More than 100,000 types of commercially synthetic dyes are known in the world. The annual production of dye is about $7 \times 10^{5}-$ $1 \times 10^{6}$ tons. From this amount, 10 to $15 \%$ discharged into the surrounding environment and water bodies as untreated effluents (Yusuf et al. 2015). Dyes are toxic and nondegradable pollutants and their presence in natural water impedes the light penetration which upset the photosynthesis of aquatic plants (Sun et al. 2013). Also, dyes can 
degrade the water quality and cause allergy, dermatitis, cancer, skin irritation, dysfunction of kidneys, liver and reproductive system in humans (Shaban et al. 2017b; Gupta et al. 2006).

Several techniques have been investigated for dye removal from water. These methods included physical, chemical and biological methods (Shaban et al. 2017c; Robinson et al. 2001). The physical methods represented by adsorption, coagulation, and filtration. Other methods also were used in the degradation of dyes such as ultrasonic power, hydrodynamic cavitational techniques, sonochemical reactors, and sonophotocatalytic degradation process (Sivakumar and Pandit 2001, 2002; Gogate et al. 2004; Panda and Sivakumar 2017). Adsorption by low-cost materials is efficient in dye removal, but such method produces a lot of solid waste (Sivakumar et al. 2013). The chemical methods involved oxidation of dye into $\mathrm{CO}_{2}$ and inorganic ions through the production of hydroxyl radical (Herrmann 1999). The hydroxyl radical can be generated by direct photolysis of oxidants as $\mathrm{O}_{3}$ and $\mathrm{H}_{2} \mathrm{O}_{2}$, with UV irradiation, Fenton, and photo-Fenton process or by photocatalytic process using semiconductors (Reza et al. 2015). The combination of the previous techniques can enhance the generation of the hydroxyl radical.

Low cost and environmental heterogeneous photocatalysts were preferred in the degradation of dyes and water remediation applications (Sivakumar et al. 2004). The main advantage of dye degradation using heterogeneous photocatalysts is the ability to profiteer the sunlight in the production of hydroxyl radicals (Shaban et al. 2017d; Sivakumar et al. 2010). In the recent period, several natural minerals such as anatase, rutile, magnetite and ilmenite possess band gap energies which qualify them for photochemical reactions (Bubacz et al. 2010). Such minerals are easily and widely available, cheap, efficient, and present in very high reserves around the world. Thus, they are future promising materials for photocatalytic degradation of organic pollutants. It has been reported that addition of $\mathrm{H}_{2} \mathrm{O}_{2}$ to dye solution in the presence of such catalysts can enhance the degradation capacity (Lucas et al. 2007). The mixture of $\mathrm{H}_{2} \mathrm{O}_{2}$ and ferrous sulfate produce hydroxyl radicals. Degradation of dyes through this process is known as Fenton's oxidation (Bandala et al. 2006). Hydroxyl radicals can also be generated from $\mathrm{H}_{2} \mathrm{O}_{2}$ in the presence of iron oxides, $\mathrm{Fe}^{3+}$-immobilized silica and $\mathrm{Fe}$-exchanged $\mathrm{Y}$ zeolite (Noorjahan et al. 2005).

To the best of our knowledge, the evaluation and application of natural chromite minerals as heterogeneous photocatalyst for degradation of organic pollutants are not investigated so far. Chromite is an oxide mineralFeO. $\mathrm{Cr}_{2} \mathrm{O}_{3}\left(68 \% \mathrm{Cr}_{2} \mathrm{O}_{3}, 32 \% \mathrm{FeO}\right)$ belonging to the spinel group and crystallizes in the isometric system. It is the main source of chromium in the world and used for various purposes in metallurgical, refractory and chemical industries (Abubakre et al. 2007). Here, we have studied the photocatalytic and photo-Fenton oxidation characterization of natural chromite for low-cost degradation of Congo red dye in water. Moreover, the effect of the operating parameters such as illumination time, initial concentration, catalyst mass and solution $\mathrm{pH}$ is addressed to investigate the degradation mechanisms of dye by fitting the resulted data to kinetic modeling. Also, we used response surface methodology (RSM) and statistical central composite rotatable design (CCRD) to evaluate the interactive effect of the selected parameters and the ideal optimum conditions for maximum removal of Congo red dye by chromite.

\section{Materials and methods}

\section{Materials and characterization}

Refined chromite sample was used as catalyst and delivered from central metallurgical research and development, represented to podiform chromite deposits, Marsa Alam, Egypt. The chemical composition of the raw chromite sample was obtained using X-ray fluorescence spectrometry (Panalytical Axios advanced XRF technique). The structure of the chromite sample was obtained by X-ray powder diffraction (XRD, Philips APD-3720) with $\mathrm{Cu} \mathrm{K} \alpha$ radiation worked at $20 \mathrm{~mA}$ and $40 \mathrm{kV}$ in the $2 \theta$ range of $5-70$ at a scanning speed of $5 \% \mathrm{~min}$. Fourier transform infrared spectrum (FT-IR-8400 S Shimadzu) was used to determine the chemical structural groups of chromite. Petrography and optical properties of the sample under reflected light were done by Nikon reflected polarized microscope attached with a computer program. The UVvisible absorption spectra of the mineral sample were measured using Shimadzu UV spectrophotometer (M160 PC) at wavelength number range from 200 to $900 \mathrm{~nm}$ at room temperature using dimethylsulfoxide (DMSO) as a solvent and reference.

\section{Photocatalytic and photo-Fenton oxidation studies}

Degradation of Congo red dye was carried out to evaluate the photocatalytic and photo-Fenton oxidation characterization of natural chromite mineral. Congo red dye was purchased from Sigma-Aldrich Company, Egypt. Sodium hydroxide and hydrochloric acid were used for modifying the $\mathrm{pH}$ of the solutions. Hydrogen peroxide $30 \% \mathrm{w} / \mathrm{v}$ was used as an oxidant to enhance the degradation of Congo red dye. The degradation experiments were conducted under artificial visible light irradiations lamp (blended metal halide lamp $400 \mathrm{~W}$ ). The experiments were performed as a function of illumination time, chromite dose, the initial 
concentration of dye and $\mathrm{pH}$, either in the presence or absence of $\mathrm{H}_{2} \mathrm{O}_{2}$. All the photocatalytic degradation tests were performed after adsorption-desorption equilibrium of Congo red dye using chromite.

\section{Effect of illumination time}

The effect of illumination time on the degradation of Congo red dye was carried out by stirring $0.04 \mathrm{gm}$ of chromite with $100 \mathrm{~mL}$ of the dye solutions $(25 \mathrm{mg} / \mathrm{L})$ for different time intervals $(1,2,4,6,8,10$ and $12 \mathrm{~h})$. The same tests were performed again after adding $1 \mathrm{~mL}$ of $\mathrm{H}_{2} \mathrm{O}_{2}$ to the solution. Then the dye solutions were separated by centrifuge to determine the dye concentration by $\mathrm{UV}-\mathrm{V}$ is spectrophotometer.

\section{Effect of photocatalyst mass}

Effect of chromite amount on the degradation of dye was tested by stirring different amounts of it $(0.02,0.04,0.08$, 0.1 and $0.12 \mathrm{~g}$ ) with $100 \mathrm{~mL}$ of Congo red dye solution $(25 \mathrm{mg} / \mathrm{L})$ as separated tests for $2 \mathrm{~h}$. The experiments were performed in the absence of $\mathrm{H}_{2} \mathrm{O}_{2}$ and after adding $1 \mathrm{~mL}$ of it to the solution. Then the dye solution was separated by centrifuge to determine the rest dye concentrations.

\section{Effect of initial dye concentration}

The effect of the initial concentration was tested by stirring $0.04 \mathrm{~g}$ of chromite with $100 \mathrm{~mL}$ of the dye solutions of different initial concentrations $(10,15,20,25,30,35 \mathrm{mg} /$ $\mathrm{L})$ for $2 \mathrm{~h}$ as separated experiments. This was done in the absence of $\mathrm{H}_{2} \mathrm{O}_{2}$ and with $1 \mathrm{~mL} \mathrm{H}_{2} \mathrm{O}_{2}$. After equilibration, solids and solutions were separated; and the dye solution for analysis.

\section{Effect of $p H$}

To study the influence of $\mathrm{pH}$ on degradation process, 0.04 gm from chromite was stirred with $100 \mathrm{~mL}$ of Congo red dye solutions $(25 \mathrm{mg} / \mathrm{l})$ of different $\mathrm{pH}$ values $(\mathrm{pH} 2, \mathrm{pH} 3$, $\mathrm{pH} 4, \mathrm{pH} 5, \mathrm{pH} 6, \mathrm{pH} 8, \mathrm{pH} 9$, and $\mathrm{pH} 10$ ) for $2 \mathrm{~h}$ either in the absence of $\mathrm{H}_{2} \mathrm{O}_{2}$ or after adding $1 \mathrm{~mL}$ from it. The solids and solutions were separated and collected for analysis using UV-Vis spectrophotometer.

The degradation percentage of Congo red dye was calculated according to Eq. 1.

Degradation $(\%)=\frac{100\left(C_{0}-C_{\mathrm{e}}\right)}{C_{0}}$,

where $C_{0}$ and $C_{\mathrm{e}}$ are the dye concentrations in the initial solution and the solution after treating with the photocatalyst.

\section{Statistical optimization}

Response surface methodology (RSM) associated with central composite rotatable statistical design (CCRD) of quadratic polynomial model was designed for the four selected parameters [illumination time ( 1 to $12 \mathrm{~h}$ ), initial concentration (10 to $35 \mathrm{mgL}$ ), chromite mass ( 0.02 to $0.14 \mathrm{~g})$ and $\mathrm{pH}(3$ to 5$)]$ to detect the interaction between such parameters and the predicted optimum conditions for the maximum degradation of Congo red dye. The experiments were performed based on the tests suggested by the statistical design and limited by best results obtained in the previous tests.

The data obtained were fitted to a second order polynomial equation (Eq. 2),

$$
\begin{aligned}
Y= & \beta_{0}+\sum_{i=1}^{4} \beta_{i} X_{i}+\sum_{i=1}^{4} \beta_{i i} X_{i} \\
& +\sum_{i=1}^{3} \sum_{j=i+1}^{4} \beta_{i j} X_{i} X_{j},
\end{aligned}
$$

where $\mathrm{Y}$ is the removal of dye $(\%) ; \beta_{0}, \beta_{i}, \beta_{i i}, i j$ are the constant coefficients $X_{\mathrm{i}}$ are the uncoded independent variables. Subsequent regression analyses, analyses of variance (ANOVA) and response surfaces were performed using the Design Expert Software (version 6.0.5). Optimal reaction parameters for maximum removal were generated using the software's numerical optimization function.

\section{Results and discussion}

\section{Characterization}

XRD pattern of the chromite concentrate was represented in Fig. 1a. The sample composed mainly of chromite as the dominant mineral phase. It was detected with their characteristic peaks at $2 \theta=18.89^{\circ}, 30.87^{\circ}, 36^{\circ}, 43.6^{\circ}$, and $63^{\circ}$. The main characteristic peak at $2 \theta 36^{\circ}$ is corresponding to the crystal plane with Miller indices of 311 , which is the characteristic peak of face-centered cubic spinel. The detected sharp peaks of chromite revealed its excellent crystallinity, which is promising for photocatalytic reaction.

The average crystallite size $(D)$ of chromite was calculated according to the Scherrer equation $(D=(0.9 \lambda) / \mathrm{W}$ $\operatorname{Cos}(\theta))$. Where $\mathrm{W}$ is the full width at half maximum in radians, $\theta$ is the Bragg's angle, and $\lambda$ is the $\mathrm{X}$-ray wavelength $(\mathrm{CuK} \alpha=0.15405 \mathrm{~nm})$. The calculated $D$ is about $22.7 \mathrm{~nm}$. Also, the average microstrain is estimated to be $0.4611 \%$. The positive sign of microstrain indicates that the stress in the natural chromite is tensile in nature. To gain more information on the number of defects in the natural chromite, the dislocation density $(\delta)$ is estimated using Williamson and Smallman's relation, $\delta=\frac{N}{D^{2}}$. Where $N$ is a 
Fig. 1 a XRD pattern of the chromite sample, b FT-IR spectrum of chromite, c morphological and optical properties of chromite under reflected light microscope (between crossed Nicole), and d UV-Vis absorbance spectrum of chromite
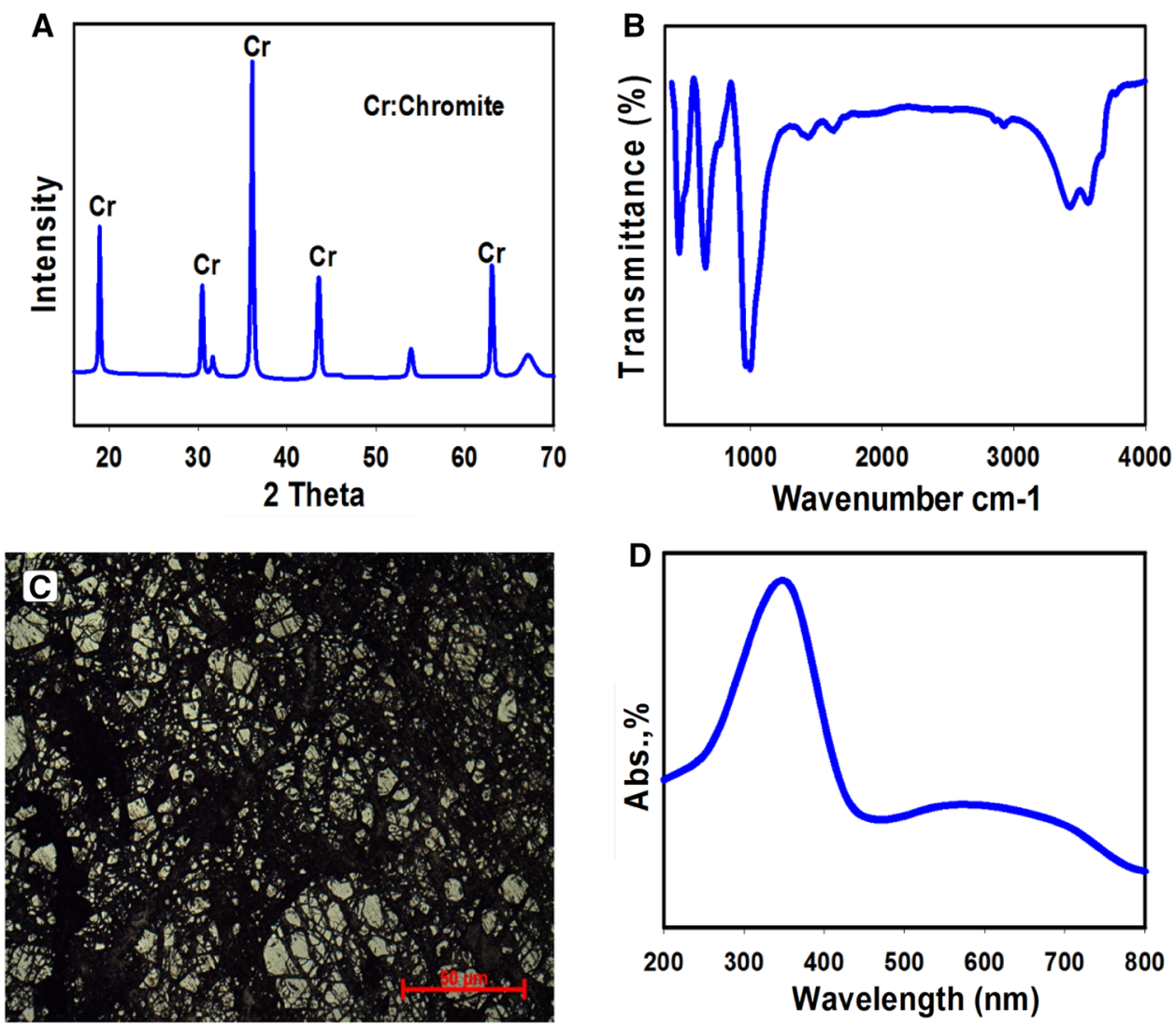

factor equals unity for the minimum dislocation density. The values of minimum $\delta$ are $1.94 \times 10^{-3}$ dislocation/ $\mathrm{nm}^{2}$, which imply a good lattice structure of the chromite sample.

Figure $1 \mathrm{~b}$ illustrates the FT-IR spectrum of the natural chromite sample. The present absorption bands at wavenumber from 500 to $1000 \mathrm{~cm}^{-1}$ were attributed to the bond between groups II and III transition metal cations in spinel oxides and oxygen anion (Moroz et al. 2001). The FT-IR bands at $\left(500-600 \mathrm{~cm}^{-1}\right)$ were assigned for the stretching vibration of $\mathrm{Cr}-\mathrm{O}$ for the chromite mineral (Durrani et al. 2012). The other detected bands were attributed to the present minerals contaminations, especially of serpentine or any other silicate minerals (Ucbas et al. 2014).

Under reflected light microscope, the chromite minerals appear as cataclastic grains of medium gray color (Fig. 1c). The chromite grains are of different shapes, sizes and occur as separated grains or in aggregated form. Light reflectivity from chromite surface was measured using reflected polarized light microscope (Fig. 1c). It commonly shows low reflection value that range from 11.5 to 13.3 at wavelength $546 \mathrm{~nm}$ and from 11.5 to 13 at wavelength $589 \mathrm{~nm}$ (Ineson 1989). The mean value of light reflection by the studied chromite sample was determined, and it is about 12.84; this value is close to the value obtained by Ineson (1989).

The optical properties of chromite are a critical parameter for the application of it in optoelectronic devices. The ultraviolet-visible absorbance spectrum of chromite is represented in Fig. 1d. The diagram shows two main absorption peaks, the first around 350 and $370 \mathrm{~nm}$ in the UV region and the second peak around 550 and $630 \mathrm{~nm}$ in the visible region. The detected spectral band in the UV region is characteristic to the optical absorption band of the chromite spinels (Durrani et al. 2012). This band is attributed to the assignments of $\mathrm{Cr}^{3+}$ ions in the octahedral sites. The other band in the visible region may be related to Fe ions in the spinel structure.

Major oxides of the refined chromite sample from XRF analysis listed in Table 1. Data from the table revealed that the sample is of the high-quality type with $\mathrm{Cr}_{2} \mathrm{O}_{3}$ content $56.7 \%$. The present iron oxide is represented by $24.5 \%$ ferrous oxide and about $4 \%$ ferric iron oxide, which indicates that the chromite sample is Fe-chromite. The rest of oxides $\left(\mathrm{CaO}, \mathrm{MgO}, \mathrm{Al}_{2} \mathrm{O}_{3}\right.$, and $\left.\mathrm{SiO}_{2}\right)$ are present in minor amounts and the total percentage of them is about $15 \%$. 
Table 1 The level and range of independent variables chosen for the removal of Congo red dye from aqueous solution

\begin{tabular}{llllcr}
\hline Factor & Name & Low actual & High actual & Low coded & High coded \\
\hline A & Illumination time & $1 \mathrm{~h}$ & $12 \mathrm{~h}$ & -1 & 1 \\
$\mathrm{~B}$ & Initial concentrations & $10 \mathrm{mg} / \mathrm{L}$ & $35 \mathrm{mg} / \mathrm{L}$ & -1 & 1 \\
$\mathrm{C}$ & Chromite mass & $0.02 \mathrm{~g}$ & $0.14 \mathrm{~g}$ & -1 & 1 \\
$\mathrm{D}$ & $\mathrm{pH}$ & 3 & 5 & -1 & 1 \\
\hline
\end{tabular}

\section{Photocatalytic and photo-Fenton oxidation behavior of chromite}

Fe-chromite is a molecular compound with chemical formula $\mathrm{FeCr}_{2} \mathrm{O}_{4}$ with spinel structure (Abubakre et al. 2007). In general, spinel minerals are binary oxide materials. In the case of Fe-chromite, it contains ferrous oxide $(\mathrm{FeO})$ and chromium oxide $\left(\mathrm{Cr}_{2} \mathrm{O}_{3}\right)$. $\mathrm{Fe}^{+2}$ ions occupy the tetrahedron sites, and $\mathrm{Cr}^{+3}$ ions occupy the octahedral sites in the spinel structure (Fig. 2). Therefore, chromite contains two functional groups of $\mathrm{Cr}_{2} \mathrm{O}_{3}$ and $\mathrm{FeO}$. Such chemical functional groups give chromite mineral photocatalytic and photo-Fenton oxidation properties (Singh et al. 2015).

Chromium (III) oxide $\left(\mathrm{Cr}_{2} \mathrm{O}_{3}\right)$ is a p-type semiconductor with wide band gap energy (Santulli et al. 2011). Under the irradiation of UV light, the outer surface electrons from chromium octahedral sites can be excited from the valence band to the conduction band. This will result in the formation of the electron-hole pair in the valence band (Reza et al. 2015). The holes can react with an electron donor (water molecules or hydroxide ions) and produce oxidizing free radical (hydroxyl radical), which will oxidize dyes on the surface (Ng et al. 2012; Akbal 2005). Also, the holes can oxidize the dye pollutants by direct electron transfer (Reza et al. 2015). Such mechanism can be summarized in Fig. 2 and in Eqs. 3-6 (Akbal 2005):
$\mathrm{Cr}_{2} \mathrm{O}_{3}+\mathrm{hv} \rightarrow \mathrm{e}_{\mathrm{CB}}^{-}+\mathrm{h}_{\mathrm{VB}}^{+}$,

$\mathrm{h}_{\mathrm{VB}}^{+}+\mathrm{H}_{2} \mathrm{O} \rightarrow \mathrm{H}^{+}+\mathrm{OH}^{\prime}$,

$\mathrm{OH}^{\circ}+$ Dyes $\rightarrow$ Degredation,

$\mathrm{h}_{\mathrm{VB}}^{+}+$Dyes $\rightarrow$ Oxidation of dyes.

Besides its role as photocatalytic oxide, $\mathrm{FeO}$ acts as the active radical for Fenton's and photo-Fenton oxidation in the natural chromite. In the Fenton's oxidation reactions, the ferrous ions react with hydrogen peroxide and from free hydroxyl radicals (Torrades et al. 2008). The presence of light enhances the oxidation of dyes as it accelerates the reduction of ferric ions into ferrous ions and promotes the direct formation of hydroxyl radicals (Feng et al. 2003). $\mathrm{Fe}^{+2}$ in this process is regenerated again through the socalled Fenton-like reaction between $\mathrm{Fe}^{+3}$ and $\mathrm{H}_{2} \mathrm{O}_{2}$. The Fenton oxidation reaction can be written as in Eqs. 7-11 (Abou-Gamra 2014):

$$
\begin{aligned}
& \mathrm{Fe}^{2+}+\mathrm{H}_{2} \mathrm{O}_{2} \rightarrow \mathrm{OH}+\mathrm{Fe}^{3+}+\mathrm{OH}^{-}, \\
& \mathrm{Fe}^{3+}+\mathrm{H}_{2} \mathrm{O}_{2} \leftrightarrow \mathrm{Fe}-\mathrm{OOH}^{2+}+\mathrm{H}^{+}, \\
& \mathrm{Fe}-\mathrm{OOH}^{2+} \rightarrow \mathrm{HO}_{2}+\mathrm{Fe}^{2+}, \\
& \mathrm{Fe}^{3+}+\mathrm{HO}_{2} \leftrightarrow \mathrm{Fe}^{2+}+\mathrm{O}_{2}+\mathrm{H}^{+},
\end{aligned}
$$

A

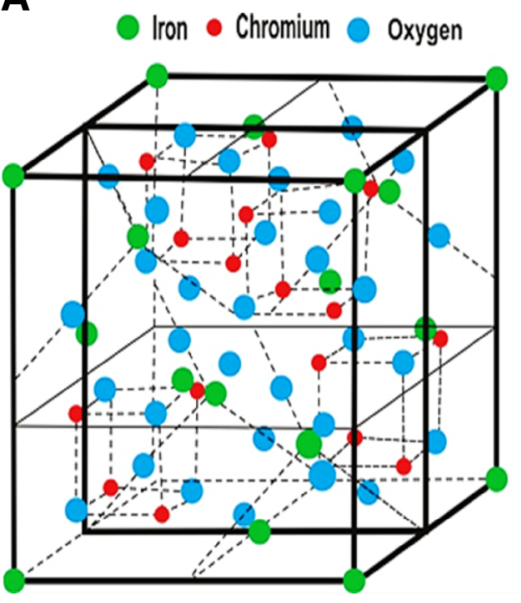

B

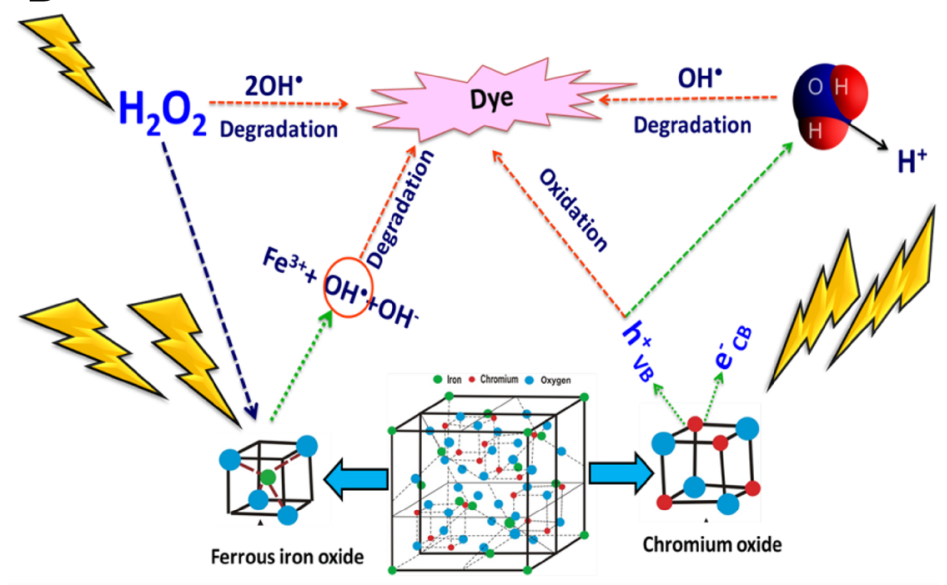

Fig. 2 a Crystal structure of Fe-chromite mineral, $\mathbf{b}$ mechanisms of photocatalytic degradation and photo-Fenton oxidation of dye by chromite 
$\mathrm{Fe}^{3+}+\mathrm{UV}+\mathrm{H}_{2} \mathrm{O} \rightarrow \mathrm{OH}^{-}+\mathrm{Fe}^{2+}+\mathrm{H}^{+}$.

Figure 3 shows the removal of Congo red dye using UV only without chromite, using $\mathrm{H}_{2} \mathrm{O}_{2}$ only without UV and chromite, using $\mathrm{H}_{2} \mathrm{O}_{2}$ and $\mathrm{UV}$ without chromite, using chromite without light and $\mathrm{H}_{2} \mathrm{O}_{2}$, using chromite in the presence of light and using chromite in the presence of light and $\mathrm{H}_{2} \mathrm{O}_{2}$. At the upper limit of reaction time $(12 \mathrm{~h})$, the removal percentage of Congo red dye reaches $8.43 \%$ using the light source only, $17.3 \%$ using $\mathrm{H}_{2} \mathrm{O}_{2}$ only, $24.32 \%$ using the light source and $\mathrm{H}_{2} \mathrm{O}_{2}$ without the catalyst, $16.78 \%$ using chromite without light source and $\mathrm{H}_{2} \mathrm{O}_{2}, 54.6 \%$ using chromite in the presence of light and $60 \%$ using chromite in the presence of light and $1 \mathrm{~mL}$ $\mathrm{H}_{2} \mathrm{O}_{2}$. The adsorption capacity of chromite and the photolysis effect of the light source reflect the photocatalytic and photo-Fenton oxidation properties of chromite.

\section{Degradation of Congo red dye}

\section{Effect of illumination time}

The relation between the illumination time and the degradation percentage of Congo red dye appears in Fig. 3. From the figure, the degradation of Congo red using chromite increased from 23.6 to $54.6 \%$ with increasing the illumination time from $1 \mathrm{~h}$ to $12 \mathrm{~h}$. The addition of hydrogen peroxide caused rising in the degradation efficiency, where the degradation value increased from 24.17 to $60 \%$ in the same time range. The effect of hydrogen

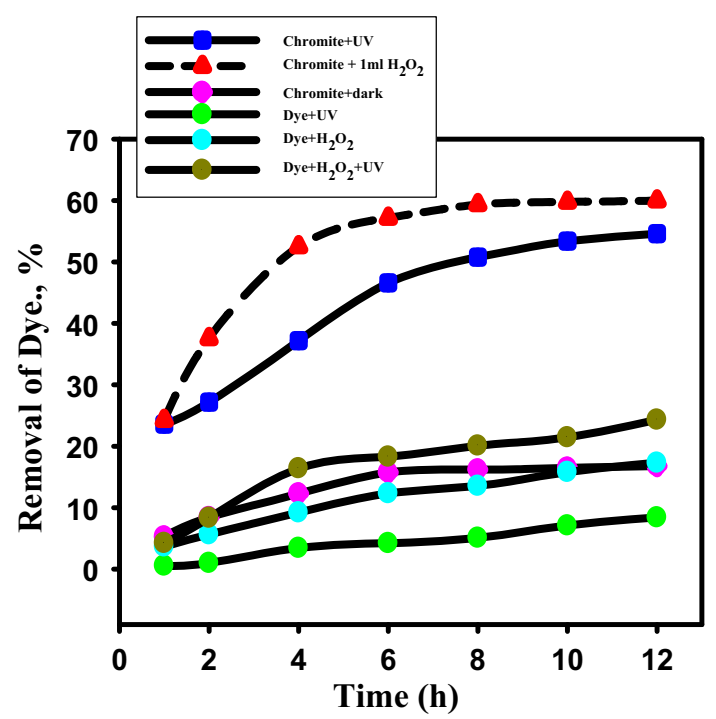

Fig. 3 Effect of illumination time on the removal of Congo red dye using chromite $+\mathrm{UV}$, chromite $+\mathrm{UV}+\mathrm{H}_{2} \mathrm{O}_{2}$, chromite without $\mathrm{UV}$ or $\mathrm{H}_{2} \mathrm{O}_{2}$, UV only without chromite or $\mathrm{H}_{2} \mathrm{O}_{2}, \mathrm{H}_{2} \mathrm{O}_{2}$ only without chromite or $\mathrm{UV}$ and $\mathrm{UV}+\mathrm{H}_{2} \mathrm{O}_{2}$ without chromite peroxide related to their reaction with ferrous oxide within chromite lattice. This response resulted in the formation of active hydroxyl radicals as in Eq. (7), as well as other hydroxyl radicals produced from the photolysis of hydrogen peroxide under the effect of light as in Eq. 12 (Muruganandham and Swaminathan 2004):

$\mathrm{H}_{2} \mathrm{O}_{2}+\mathrm{Uv} \rightarrow \mathrm{OH}^{-}+\mathrm{OH}^{\circ}$.

It is worth to be mentioned that while the degradation of Congo red dye by chromite increased gradually with contact time, there is a deviation from the behavior in the presence of hydrogen peroxide. The degradation curve with the contact time shows nearly constant values with increasing the illumination time from 8 to $12 \mathrm{~h}(59.4$ to $60 \%)$. This can be attributed to the consumption of $\mathrm{H}_{2} \mathrm{O}_{2}$ and $\mathrm{Fe}^{+2}$, which reduce the rate of dye degradation (Alalm et al. 2015).

\section{Kinetic studies}

Three kinetic models were used (zero, first order, and second order kinetic models) to investigate the degradation of Congo red dye using chromite in the presence and absence of $\mathrm{H}_{2} \mathrm{O}_{2}$. The three kinetic models were expressed as in Eqs. 13-15 for zero, first order, and second order kinetic models, respectively (Sun et al. 2009):

$\frac{\mathrm{d} c}{\mathrm{~d} t}=-k_{0}$,

$\frac{\mathrm{d} c}{\mathrm{~d} t}=-k_{1} c$

$\frac{\mathrm{d} c}{\mathrm{~d} t}=-k_{2} c^{2}$,

where $\mathrm{C}$ is the concentration of Congo red dye; $k_{0}, k_{1}$, and $k_{2}$ are the apparent kinetic rate constants of zero, first and second order reaction kinetics, respectively; $t$ is the reaction time.

Equations 16-18 resulted from the integrations of Eqs. 13-15 (Sun et al. 2009):

$C_{\mathrm{t}}=C_{0}-k_{0} t$

$C_{\mathrm{t}}=C_{0} e^{-k_{1} t}$

$\frac{1}{C_{\mathrm{t}}}=\frac{1}{C_{0}}+k_{2} t$,

where $C_{t}$ is the concentration of Congo red dye after illumination time $(t)$.

The zero order kinetic model was represented by regression plotting of $C_{\mathrm{t}}$ versus time (Fig. 4a) and the first order kinetic model was investigated from the linear relation between In $\left(\mathrm{C}_{0} / \mathrm{C}\right)$ and time (Fig. $\left.4 \mathrm{~b}\right)$. While the second order kinetic model was studied through the linear relation between $1 / C_{\mathrm{t}}$ and time (Fig. $4 \mathrm{c}$ ). The kinetic 

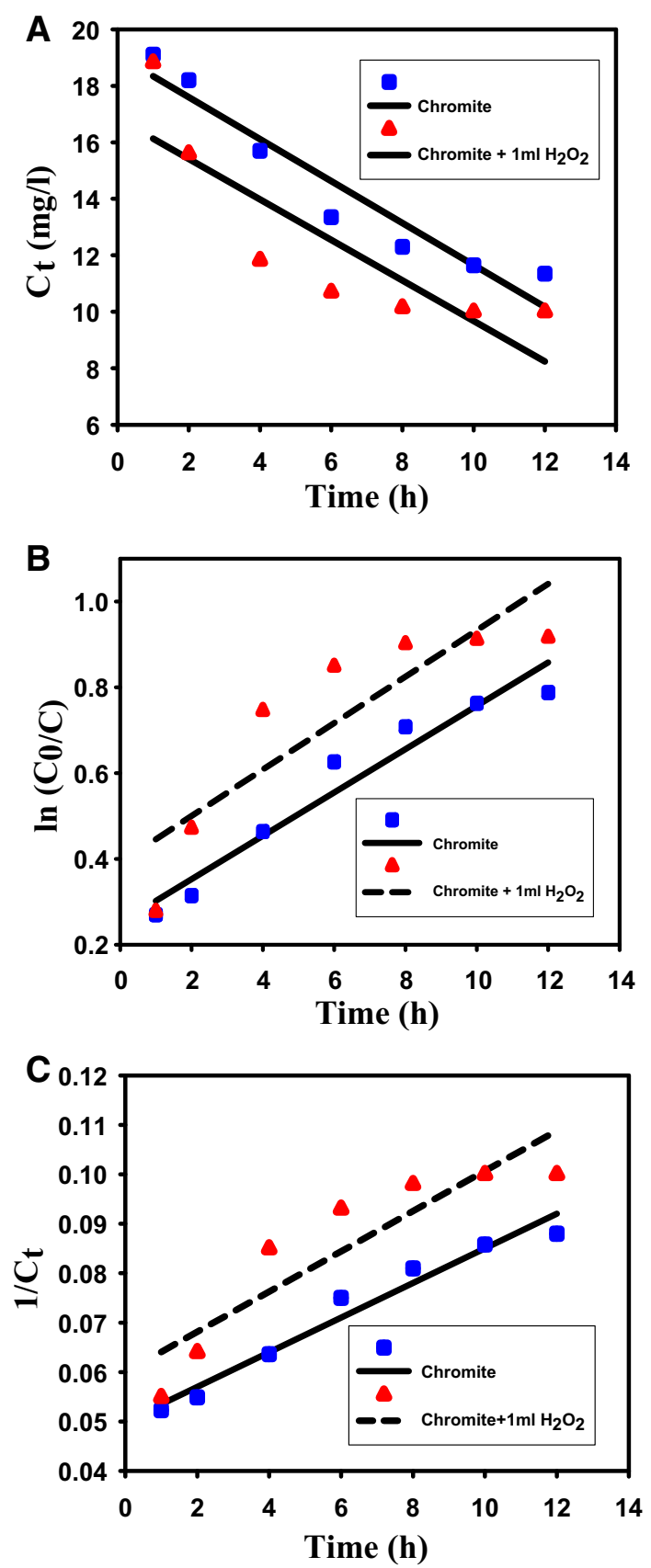

Fig. 4 a Linear relation of zero order kinetic model, b linear relation of the first order kinetic model, c linear relationship of the second order kinetic model

parameters for the selected models were listed in Table 2 . By comparing the correlation coefficient $\left(R^{2}\right)$ value from the three models, it can be seen that $R^{2}$ values based on the second order kinetic model were 0.96 and 0.82 for degradation by chromite only and after addition of $\mathrm{H}_{2} \mathrm{O}_{2}$, respectively. Therefore, second order kinetic model was much better than zero order and first order kinetic models to represent the photocatalytic degradation and photoFenton oxidation of Congo red dye in solution (Table 2).
Also, the $R^{2}$ values indicated the better fit of the photocatalytic degradation process with the kinetic models as compared to photo-Fenton oxidation after the addition of $\mathrm{H}_{2} \mathrm{O}_{2}$. Photo-Fenton oxidation of Congo red dye using chromite show only medium fitting with the second order kinetic model $\left(R^{2}=0.82\right)$. Well fitting of the photocatalytic degradation results with the three kinetic models revealed that there are parallel mechanisms operated during the degradation of Congo red dye (Wang et al. 2008).

The values of the kinetic rate constants for the photoFenton oxidation process were greater than the values for the photocatalytic degradation process. This confirmed that the degradation efficiency of Congo red dye by chromite is better after the addition of $\mathrm{H}_{2} \mathrm{O}_{2}$, i.e., by photo-Fenton oxidation process (Alalm et al. 2015).

\section{Effect of chromite mass}

The effect of chromite mass on the degradation process either based on the photocatalytic degradation or photoFenton oxidation after the addition of $\mathrm{H}_{2} \mathrm{O}_{2}$ was represented in Fig. 5a. From the figure, the removal efficiency of Congo red dye increased by 20, 27, 36.8, 41.2 and $44 \%$ with increasing the chromite mass by $0.02,0.04,0.08,0.1$ and $0.12 \mathrm{gm}$, respectively. With the addition of $1 \mathrm{~mL} \mathrm{H}_{2} \mathrm{O}_{2}$ to the system, the removal efficiency increased by 27.6 , $37.5,46.4,53.2$ and $60.4 \%$ with the same applied chromite mass. This might be attributed to the increase in the produced hydroxyl radicals with increasing the chromium and ferrous oxide according to Eqs. 5 and 9 (Huang et al. 2008).

Galindo et al. (2001) set an empirical relation between the degradation rate and the mass of the used catalyst $\left(r^{\circ} \propto\right.$ $[\mathrm{MC}]^{n}$ [dye]), where $r^{\mathrm{o}}$ is the reciprocal initial rate, $\mathrm{MC}$ is the mass of the used catalyst and $\mathrm{n}$ is an exponent less than 1 for the studied dye, in relation to low mass of the used catalyst. The relation was represented by linear regression plot of ln (chromite mass) versus Ln (lo) with high correlation coefficient $\left(R^{2}=1\right)$ in Fig. 5b. The results revealed that the degradation rate depends on the chromite mass and follows a similar relationship $\left(r^{\mathrm{O}} \propto\left[\mathrm{TiO}^{2}\right] 0.93\right)$ reported by Galindo et al. (2001).

\section{Effect of initial concentration}

The relationship between Cong red dye initial concentration and the degradation efficiency by chromite, either in the absence or presence of $\mathrm{H}_{2} \mathrm{O}_{2}$ is shown in Fig. 6. The degradation of Congo red dye was decreased by $62,49.85$, $35.2,27.2,26.7$ and $25.5 \%$ with increasing the initial dye concentration by $10,15,20,25,30$ and $35 \mathrm{mg} / \mathrm{L}$ using chromite without $\mathrm{H}_{2} \mathrm{O}_{2}$. Within the same initial dye concentrations, the degradation after adding of $\mathrm{H}_{2} \mathrm{O}_{2}$ was 
Table 2 Major oxides of the refined chromite sample

\begin{tabular}{lc}
\hline Major oxides & Percentage (\%) \\
\hline $\mathrm{Cr}_{2} \mathrm{O}_{3}$ & 56.7 \\
$\mathrm{Fe}_{2} \mathrm{O}_{3}$ & 4 \\
$\mathrm{FeO}$ & 24.5 \\
$\mathrm{CaO}$ & 2.3 \\
$\mathrm{MgO}$ & 6.3 \\
$\mathrm{Al}_{2} \mathrm{O}_{3}$ & 3.5 \\
$\mathrm{SiO}_{2}$ & 2.85 \\
Loss on ignition & 4 \\
\hline
\end{tabular}
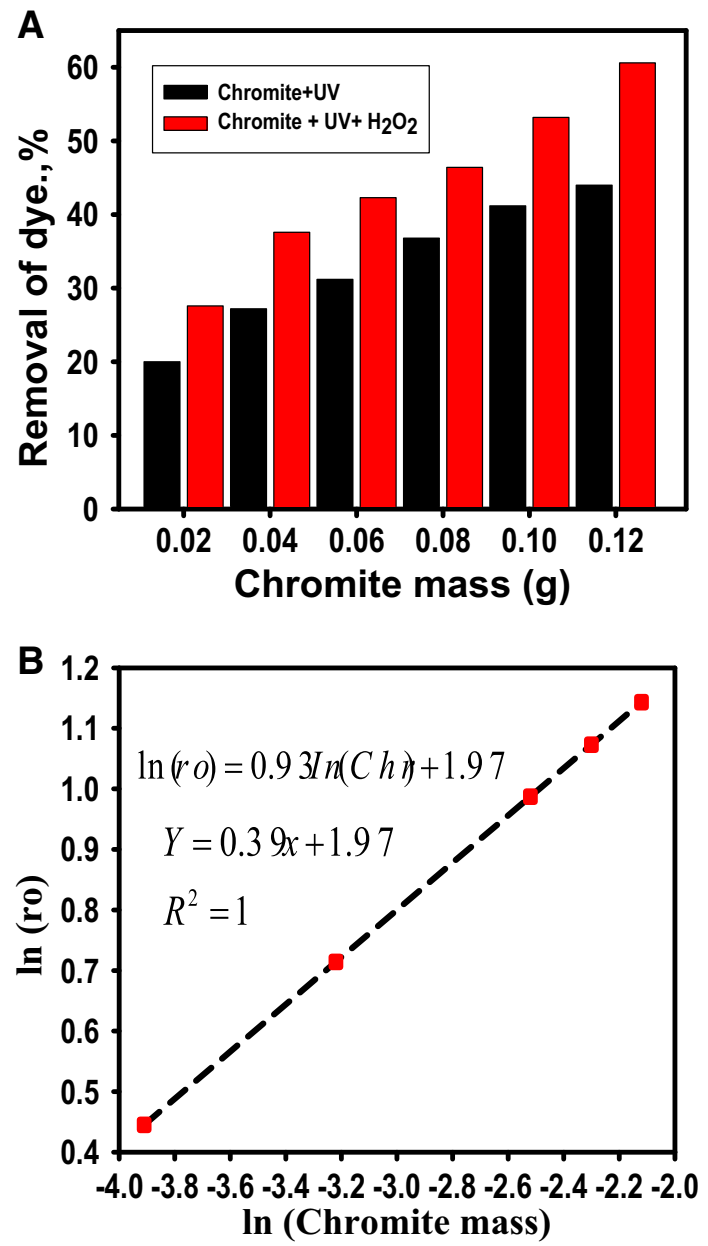

Fig. 5 a The effect of chromite mass on the degradation of Congo red dye, $\mathbf{b}$ the relation between $r^{\circ}$ and the chromite mass

reduced by $74,65,48.9,37.7,30.5$, and $27.3 \%$. This behavior may be related to the fact that increasing the initial dye concentration causes increasing in the amount of adsorbed dye on the surface of chromite. Therefore, the production of hydroxyl radical will be decreased as there are only a fewer available active sites for adsorption of

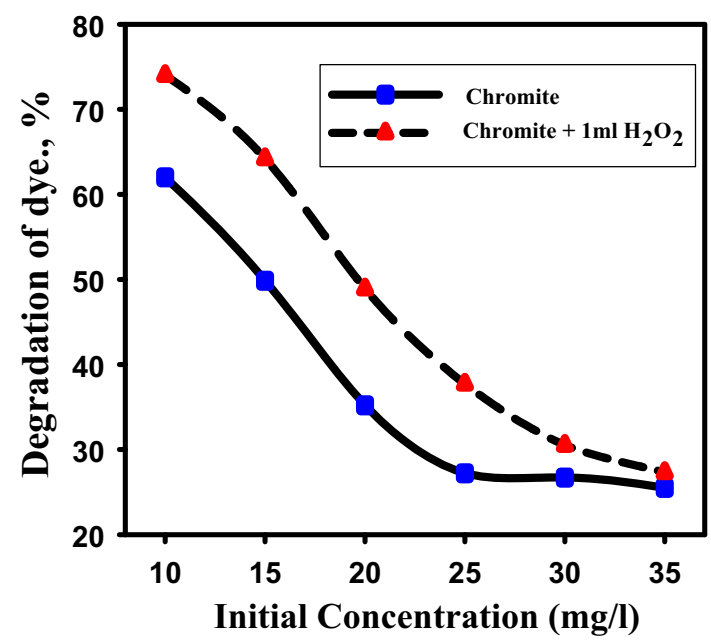

Fig. 6 Effect of initial Congo red dye concentration on the degradation efficiency

hydroxyl ions and the generation of hydroxyl radicals (Behnajady et al. 2006). Also increasing dye concentration will act as blocking surface between the photons and the catalyst surface. Hence, the absorption of a photon by chromite will decrease, and it turn the degradation efficiency will decrease.

\section{Effect of $p H$}

The effect of $\mathrm{pH}$ value on the degradation of Congo red dye by chromite before and after the addition of $\mathrm{H}_{2} \mathrm{O}_{2}$ in the system represented in Fig. 7. The degradation decreased gradually from $33 \%$ to $12.9 \%$ with increasing the $\mathrm{pH}$ value from 3 to 10 in the case of chromite without $\mathrm{H}_{2} \mathrm{O}_{2}$. Decreasing the removal efficiency with increasing the $\mathrm{pH}$ value might me related to the protonation of the chromite surface at acidic conditions $(\mathrm{pH}<4)$. Thus, the active site became positively charged which enhances the adsorption of acidic dyes such as Congo red dye (Abudaia et al. 2013). This, in turn, supports the degradation and oxidation of dye anions. However, at higher $\mathrm{pH}$ values, the dye anions repel far from the negatively charged chromite surface, so degradation ratio decreases.

While in the presence of $\mathrm{H}_{2} \mathrm{O}_{2}$ the degradation efficiency increased from 35 to $37.6 \%$ with increasing the $\mathrm{pH}$ value from 3 to 4 . Then the degradation decreases with increasing the $\mathrm{pH}$ from 4 to become $14.6 \%$ at $\mathrm{pH} 10$, i.e., $\mathrm{pH} 4$ is the optimum value. $\mathrm{pH}$ value of the solution plays a significant role in the Fenton oxidation process as it influences the generation of hydroxyl radicals and the concentration of ferrous ions (Ercan et al. 2015). Below pH 4 , the reduction in the degradation rate was attributed to the scanning of the hydroxyl radicals with hydrogen ions (Bahmani et al. 2013). Also under such high acidic 


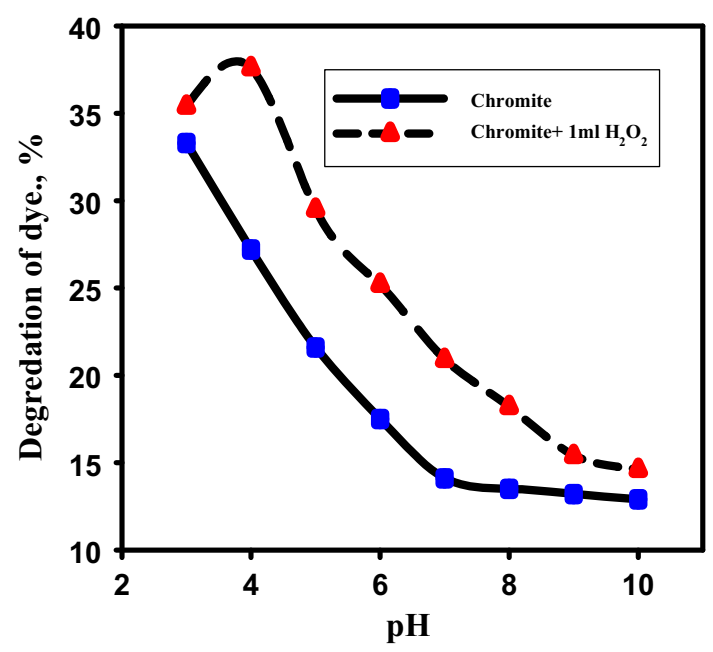

Fig. 7 Effect of the initial solution $\mathrm{pH}$ on the removal of dye

conditions, the present hydrogen peroxide can capture a proton and form $\mathrm{H}_{3} \mathrm{O}_{2}{ }^{+}$. Therefore, the used hydrogen peroxide will become electrophilic causing reduction in the reactivity between hydrogen peroxide and ferrous ions (Herney-Ramirez et al. 2008).

At alkaline conditions $(\mathrm{pH}>4)$, the degradation efficiency was decreased as a result of reducing the oxidation potential of hydroxyl radicals (Sun et al. 2007), precipitation of $\mathrm{Fe}(\mathrm{OH})_{3}$ which reduce the concentration of dissolved $\mathrm{Fe}^{3+}$, and finally the less stability of hydrogen peroxide at alkaline conditions (Rodrigues et al. 2009). All the previous conditions will result in decreasing the produced hydroxyl radicals, and hence the degradation efficiency of Congo red dyes by chromite through a photoFenton oxidation process.

\section{Statistical analysis and optimization}

\section{Fitness of the model}

The experimental runs which were designed by the central composite rotatable statistical design (CCRD) and the required responses (degradation of Congo red dye \%) are shown in Table 3. The second order quadratic polynomial statistical model was selected to represent the relations between the operating parameters (illumination time, chromite mass, the initial concentration of Congo red dye, and $\mathrm{pH}$ ) and the removal efficiency of dye. Model F-values for the removal of dyes by photocatalytic degradation and photo-Fenton oxidation were obtained from the analysis of variance (ANOVA). The model F-values are 55.5 and 62.6 for photocatalytic degradation and photo-Fenton oxidation, respectively. These values indicate the high significances of used models with only a $0.01 \%$ noise for the designs.
The mathematical regression equations of the quadratic polynomial model, which represent the relations between the removal of Congo red dye (\%) and the operating parameters, were obtained from Design Expert Software (Version 6.0.5) and expressed for coded units as follows:

$Y 1=+60.97+17.49 \times \mathrm{A}-19.67 \times \mathrm{B}+14.12 \mathrm{X}$ $\mathrm{C}-3.46 \mathrm{X} \mathrm{D}-13.31 \mathrm{X} \quad \mathrm{A} 2+7.95 \times \mathrm{B}^{2}-7.73 \mathrm{X}$ $\mathrm{C}^{2}-0.23 \mathrm{X} \mathrm{D}^{2}+1.38 \mathrm{XAX} \mathrm{X}+1.18 \mathrm{X} \mathrm{AXC}+0.75$ X A X D -2.62 X B X C -0.15 X B X D -0.96 X C X $\mathrm{D}$

$Y 2=+73.49+17.78 \times \mathrm{A}-18.44 \times \mathrm{B}+12.72 \mathrm{X}$ $\mathrm{C}-2.84 \mathrm{X} \mathrm{D}-14.61 \times \mathrm{A}^{2}+6.53 \mathrm{X} \mathrm{B}^{2}-4.96 \mathrm{X}$ $\mathrm{C}^{2}-3.06 \mathrm{X} \mathrm{D}^{2}+2.42 \times \mathrm{A} \mathrm{X} \mathrm{B}-0.33 \times \mathrm{A} \mathrm{X} \mathrm{C}+0.42$ X A X D -0.15 X B XC -0.34 X B X D + 0.53X CX D.

Where $Y 1$ and $Y 2$ are the removal of Congo red dye by photocatalytic degradation and photo-Fenton, respectively, $\mathrm{A}$ is the illumination, $\mathrm{B}$ is the initial dye concentration, $\mathrm{C}$ is the chromite mass and $\mathrm{D}$ is the $\mathrm{pH}$ value.

The regression plot between the actual removal of dye from the experimental tests and the predicted results obtained using the model equations show good agreement with a high determination coefficient $\left(R^{2}>0.9\right)$ (Fig. 8). This gave an indication of the significance of the quadratic polynomial model and its suitability to represent the actual relations between the removal efficiency and the selected variables.

\section{Interaction effect and optimization}

The interaction effect between the operating parameter was expressed in 3D response surface diagrams (Fig. 9). Response surface plots regarding two selected factors at any time maintaining all other factors at fixed levels are suitable in understanding the effect of the main parameters and the interaction between them and can be represented by 3D diagrams. The elliptical shape of the curve designates a good interaction of the two variables, and circular shape indicates no interaction between the variables (Abukhadra et al. 2015).

The diagram revealed that the effect of each parameter on the degradation behavior is fixed at any given value for the other parameters. However, the degradation efficiency is controlled by the interaction effect of the other parameters.

The interaction effect of the operating parameters on the photocatalytic degradation of Congo red dye using chromite alone without $\mathrm{H}_{2} \mathrm{O}_{2}$ is shown in Fig. 9. The degradation of dye is increased with increasing the illumination time from 1 to $12 \mathrm{~h}$ at any given value for the other factors (Fig. 9a-c). However, the degradation capacity was controlled mainly by the interaction effect of the initial concentration. At fixed conditions of $\mathrm{pH} \mathrm{4,} 0.08 \mathrm{~g}$ chromite 
Table 3 Parameters of studied kinetic models

\begin{tabular}{llll}
\hline Kinetic model & Parameters & Chromite $+\mathrm{UV}$ & $\mathrm{Chromite}+\mathrm{H}_{2} \mathrm{O}_{2}+\mathrm{UV}^{-}$ \\
\hline Zero order kinetic model & $\mathrm{k}(\mathrm{mg} / \mathrm{min})$ & 0.74 & 0.77 \\
& $\mathrm{R}^{2}$ & 0.92 & 0.72 \\
First order kinetic model & $\mathrm{K}_{1}\left(\mathrm{~min}^{-1}\right)$ & 0.05 & 0.054 \\
& $\mathrm{R}^{2}$ & 0.94 & 0.77 \\
Second order kinetic model & $\mathrm{k}_{2}(\mathrm{~L} / \mathrm{mol} \mathrm{min})$ & 0.0035 & 0.004 \\
& $\mathrm{R}^{2}$ & 0.96 & 0.82 \\
\hline
\end{tabular}

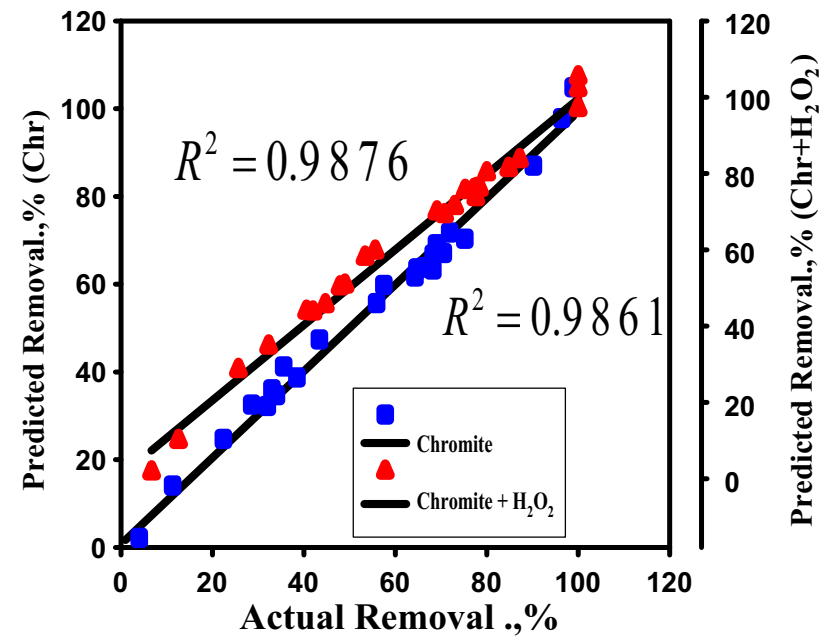

Fig. 8 Correlation between predicted removal of dye and experimental values

mass and $10 \mathrm{mg} / \mathrm{L}$ dye concentration, the removal efficiency increased from 59\% to about $91.5 \%$ with increasing the time from 1 to $12 \mathrm{~h}$. At the same operating conditions with raising the dye concentration to $35 \mathrm{mg} / \mathrm{L}$, the removal efficiency increased from 17 to $54.85 \%$ in the same time range.

The interaction effect of chromite mass with the other operating parameters is shown in Fig. 9b, d and f. At fixed illumination time $6 \mathrm{~h}$ and fixed conditions of $20 \mathrm{mgL}$ initial Congo red concentration and $\mathrm{pH} 4$, the degradation efficiency increased from 35 to $75 \%$ by increasing the chromite mass from 0.02 to $0.14 \mathrm{~g}$. Also using the optimum chromite mass $(0.14 \mathrm{gm})$, the degradation efficiency increased from $75 \%$ after $6 \mathrm{~h}$ of illumination to about $80 \%$ after $12 \mathrm{~h}$ of illumination. This revealed that the optimum illumination time, initial Congo red concentration and chromite mass are $12 \mathrm{~h}, 10 \mathrm{mg} / \mathrm{L}$ and $0.14 \mathrm{~g}$, respectively.

The interaction effect of $\mathrm{pH}$ with the other selected factors also controls the degradation efficiency of dye at any given value for the other parameters. The high acidic conditions are the optimum media for maximum degradation of dye at any given value of the other factors. At optimum conditions of time (12 h), chromite mass ( $0.14 \mathrm{~g})$ and initial dye concentration $(10 \mathrm{mg} / \mathrm{L})$, the degradation capacity increased from 96.4 to $98.9 \%$ with decreasing the solution $\mathrm{pH}$ value from 5 to 3 , respectively (Fig. 9c, e, and f).

For the degradation of Congo red dye by photo-Fenton oxidation using chromite with $1 \mathrm{~mL} \mathrm{H}_{2} \mathrm{O}_{2}$, the removal efficiency shows noticeable increasing with the illumination time from 1 to $8 \mathrm{~h}$. Then the degradation rate slightly increased from 8 to $12 \mathrm{~h}$. However, the degradation capacity with the time was controlled by the interaction effect of the other factors (Fig. 9g, h, and i). The degradation efficiency was increased from 68.5 to $99.2 \%$ by increasing the contact time from $1 \mathrm{~h}$ to $12 \mathrm{~h}$, respectively. This occurred at operating conditions of $10 \mathrm{mg} / \mathrm{L}$ initial dye concentration, $\mathrm{pH} 4$ and $0.08 \mathrm{~g}$ chromite mass. With using the upper limit for the dye concentration $(35 \mathrm{mg} / \mathrm{L})$, the degradation efficacy increased from 26.7 to $67 \%$ for the same time range.

The interaction effect of chromite mass with the effect of the other parameters was represented in Fig. 9h, $\mathrm{j}$ and $\mathrm{l}$. The interaction effect of it with the illumination time can be explained by fixed conditions of initial dye concentration $(20 \mathrm{mg} / \mathrm{L})$, illumination time $(6 \mathrm{~h})$ and $\mathrm{pH}$ (4). At these conditions, the degradation capacity increased from 53 to $87.2 \%$ with increasing the chromite mass from 0.02 to $0.14 \mathrm{~g}$, respectively. By fixing the applied mass at 0.14 gm, the degradation increased from $87.2 \%$ after $6 \mathrm{~h}$ to about $94 \%$ after $12 \mathrm{~h}$. At $10 \mathrm{mg} / \mathrm{L}$ as initial dye concentration (lower limit), $12 \mathrm{~h}$ as contact time and $\mathrm{pH} 4$, the removal of dye increased from $81.7 \%$ to about $100 \%$ by increasing the chromite mass from $0.02 \mathrm{~g}$ to $0.14 \mathrm{~g}$. This revealed that the optimum illumination time, initial Congo red concentration and chromite mass are $12 \mathrm{~h}, 10 \mathrm{mg} / \mathrm{L}$ and $0.14 \mathrm{~g}$, respectively.

In the photo-Fenton oxidation, $\mathrm{pH} 4$ is the optimum $\mathrm{pH}$ for the maximum degradation of Congo red dye. The interaction effect of the solution $\mathrm{pH}$ value with the other operating factors was represented in Fig. 9i, $\mathrm{k}$ and 1 . At fixed operating conditions of illumination time $(6 \mathrm{~h})$, 

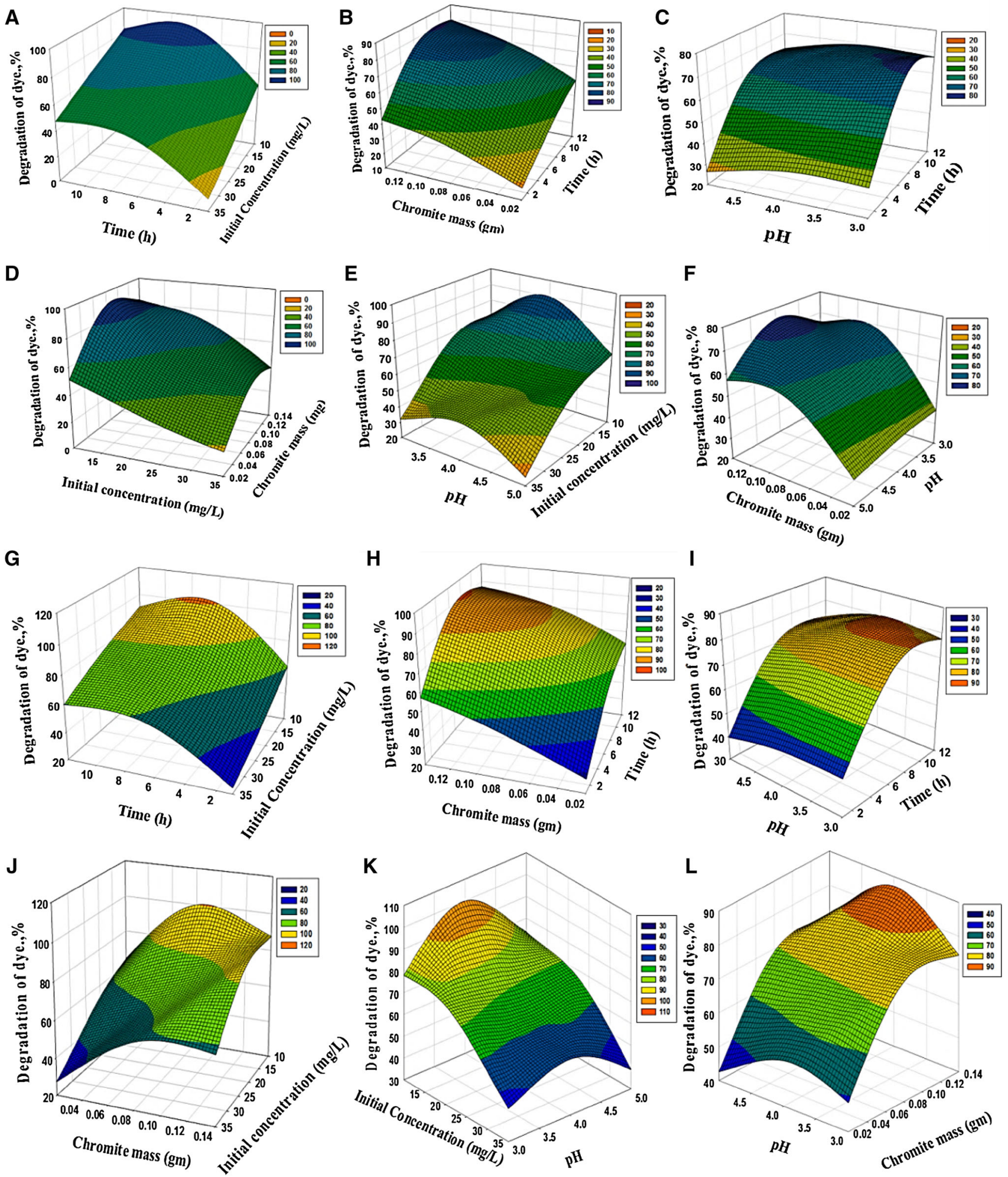

Fig. 9 3D response surface diagrams for the interaction between the operating parameters during photodegradation of Congo red dye by chromite (a-f), and Fenton's oxidation of Congo red dye by chromite ( $\mathbf{g}-\mathbf{l})$

chromite mass $(0.08 \mathrm{~g})$ and initial dye concentration $(20 \mathrm{mg} / \mathrm{L})$, the degradation capacity was investigated to be $75.3 \%$ at $\mathrm{pH} 3,77.2 \%$ and $69 \%$ at $\mathrm{pH}$ 5. While at the optimum conditions of $12 \mathrm{~h}, 0.14 \mathrm{~g}, 10 \mathrm{mg} / \mathrm{L}$ and $\mathrm{pH} 4$, the removal efficiency increased to about $100 \%$. 
Table 4 Results of the experimental runs designed according to the CCRD

\begin{tabular}{|c|c|c|c|c|c|c|}
\hline Run & Illumination time(A) & Initial concentration $(\mathrm{mg} / \mathrm{l})(\mathrm{B})$ & Chromite mass (C) & $\mathrm{PH}(\mathrm{D})$ & Chromite + UV & Chromite $+\mathrm{UV}+\mathrm{H}_{2} \mathrm{O}_{2}$ \\
\hline 1 & 12.00 & 35.00 & 0.02 & 5 & 32 & 42 \\
\hline 2 & 6.00 & 20.00 & 0.08 & 4 & 64.8 & 77.2 \\
\hline 3 & 12.00 & 35.00 & 0.14 & 5 & 55.9 & 70.8 \\
\hline 4 & 1.00 & 20.00 & 0.08 & 4 & 34 & 44.7 \\
\hline 5 & 6.00 & 20.00 & 0.08 & 5 & 57.5 & 69.1 \\
\hline 6 & 6.00 & 20.00 & 0.08 & 4 & 64.8 & 77.2 \\
\hline 7 & 12.00 & 10.00 & 0.14 & 5 & 96.4 & 100 \\
\hline 8 & 12.00 & 20.00 & 0.08 & 4 & 69 & 80 \\
\hline 9 & 1.00 & 10.00 & 0.14 & 5 & 64.3 & 73 \\
\hline 10 & 6.00 & 20.00 & 0.02 & 4 & 35.6 & 53.4 \\
\hline 11 & 1.00 & 35.00 & 0.02 & 3 & 4 & 12.6 \\
\hline 12 & 12.00 & 10.00 & 0.02 & 5 & 66.3 & 78.4 \\
\hline 13 & 12.00 & 10.00 & 0.14 & 3 & 98.9 & 100 \\
\hline 14 & 12.00 & 35.00 & 0.14 & 3 & 68.2 & 77.6 \\
\hline 15 & 6.00 & 10.00 & 0.08 & 4 & 90.2 & 100 \\
\hline 16 & 1.00 & 10.00 & 0.14 & 3 & 71.9 & 77.8 \\
\hline 17 & 1.00 & 10.00 & 0.02 & 3 & 38.5 & 49 \\
\hline 18 & 1.00 & 10.00 & 0.02 & 5 & 28.6 & 40.6 \\
\hline 19 & 12.00 & 35.00 & 0.02 & 3 & 33 & 47.9 \\
\hline 20 & 1.00 & 35.00 & 0.14 & 3 & 22.4 & 32.3 \\
\hline 21 & 6.00 & 20.00 & 0.08 & 3 & 68.3 & 75.3 \\
\hline 22 & 6.00 & 20.00 & 0.14 & 4 & 75.2 & 87.2 \\
\hline 23 & 12.00 & 10.00 & 0.02 & 3 & 70.5 & 84.8 \\
\hline 24 & 6.00 & 35.00 & 0.08 & 4 & 43.4 & 55.6 \\
\hline 25 & 1.00 & 35.00 & 0.02 & 5 & 1 & 6.7 \\
\hline 26 & 1.00 & 35.00 & 0.14 & 5 & 11.3 & 25.7 \\
\hline
\end{tabular}

Taking advantage of the quadratic programming and the statistical analysis of the design, the suggested solutions for maximum degradation of Congo red dye were obtained directly from Design Expert's optimization function. The predicted solutions for the optimum conditions with their predicted values were listed in Table 4. The statistical prediction for the suggested optimum solution revealed that $12 \mathrm{mg} / \mathrm{L}$ from Congo red dye can be completely removed (100\%) using $0.14 \mathrm{~g}$ chromite as catalyst for $11 \mathrm{~h}$ at $\mathrm{pH}$. Also, $10 \mathrm{mg} / \mathrm{L}$ from the dye can be completely removed using $0.11 \mathrm{gm}$ chromite as catalyst for $8 \mathrm{~h}$ at $\mathrm{pH} 3$. The predicted optimum conditions for the removal of Congo red dye using photo-Fenton oxidation appears in Table 5. The predicted conditions revealed that about $13.5 \mathrm{mg} / \mathrm{l}$ Congo red dye can be completely removed (100\%) using $0.10 \mathrm{~g}$ chromite in the presence of $1 \mathrm{~mL} \mathrm{H}_{2} \mathrm{O}_{2}$ for $10 \mathrm{~h}$ at $\mathrm{pH}$. Also, $10 \mathrm{mg} / \mathrm{L}$ from the dye can be completely removed using $0.08 \mathrm{gm}$ chromite in the presence of $\mathrm{H}_{2} \mathrm{O}_{2}$ for $8 \mathrm{~h}$ at $\mathrm{pH} 4$. This shows that the photo-Fenton oxidation of Congo red dye using chromite can achieve higher efficiency at lower illumination time and with smaller amounts from chromite than the photodegradation process using chromite as photocatalyst.

\section{Conclusion}

In this study, the removal of Congo red dyes from industrial water using Fe-chromite ore is investigated. The effect of the main working parameters that are influencing the dye removal such as contact time, ore mass, initial dye concentration, and medium $\mathrm{pH}$ are studied. The statistical central composite rotatable design (CCRD) and the response surface method (RSM) are used to evaluate the effect of parameters interaction and to deduce the optimum conditions for maximum dye color degradation.

Results showed that the color degradation via photocatalytic mechanism was fitting with the zero, first order and second order kinetic models. However, the photocatalytic mechanism was represented better with the second order. Meanwhile, the photo-Fenton oxidation showed moderate fitting with the second order kinetic model only. 
Table 5 The suggested solutions for the maximum removal of Congo red dye using Chromite and Chromite $+\mathrm{H}_{2} \mathrm{O}_{2}$

\begin{tabular}{|c|c|c|c|c|c|c|}
\hline Number & Contact time (min) & Initial concentration $(\mathrm{mg} / \mathrm{l})$ & Dose $(g)$ & $\mathrm{pH}$ & Removal efficiency (\%) & Desirability \\
\hline \multicolumn{7}{|c|}{ Chromite + UV } \\
\hline 1 & 10 & 10 & 0.13 & 5 & 99 & 1.000 \\
\hline 2 & 8 & 10 & 0.11 & 3 & 100 & 1.000 \\
\hline 3 & 10 & 10 & 0.12 & 4 & 99 & 1.000 \\
\hline 4 & 11 & 12 & 0.14 & 3 & 100 & 1.000 \\
\hline 5 & 8 & 10 & 0.12 & 4 & 99.6 & 1.000 \\
\hline \multicolumn{7}{|c|}{ Chromite $+\mathrm{UV}+\mathrm{H}_{2} \mathrm{O}_{2}$} \\
\hline 1 & 10 & 12.5 & 0.11 & 5 & 100 & 1.000 \\
\hline 2 & 10 & 13.5 & 0.10 & 3 & 100 & 1.000 \\
\hline 3 & 10 & 10 & 0.08 & 3 & 100 & 1.000 \\
\hline 4 & 8 & 10 & 0.08 & 4 & 100 & 1.000 \\
\hline 5 & 10.5 & 13 & 0.13 & 4 & 100 & 1.000 \\
\hline
\end{tabular}

However, the values of kinetic rate constants for the photoFenton oxidation were greater than those for the photocatalytic degradation. Therefore, the degradation of Congo red dye using chromite ore is suggested to be conducted via the photo-Fenton oxidation mechanism. Based on the response surface analysis, the predicted conditions for maximum removal of Congo red dye using chromite ore were $10 \mathrm{~h}$ illumination contact time, $0.10 \mathrm{~g}$ ore mass, $13.5 \mathrm{mg} / \mathrm{l}$ initial dye concentration, and medium $\mathrm{pH}=4$. The statistical prediction for the suggested optimum solution revealed the complete reduction of Congo red dye at initial concentration of $12 \mathrm{mg} / \mathrm{l}$ using $0.14 \mathrm{~g}$ chromite as catalyst for $11 \mathrm{~h}$ at $\mathrm{pH} 3$. On the other hands, $10 \mathrm{mg} / \mathrm{l}$ from the dye can be completely removed using $0.11 \mathrm{~g}$ chromite as catalyst after $8 \mathrm{~h}$ at $\mathrm{pH} 3$.

Open Access This article is distributed under the terms of the Creative Commons Attribution 4.0 International License (http:// creativecommons.org/licenses/by/4.0/), which permits unrestricted use, distribution, and reproduction in any medium, provided you give appropriate credit to the original author(s) and the source, provide a link to the Creative Commons license, and indicate if changes were made.

\section{References}

Abou-Gamra ZM (2014) Kinetic and thermodynamic study for Fenton-like oxidation of Amaranth red dye. Adv Chem Eng Sci 4:285-291

Abubakre OK, Murian RA, Nwokike PN (2007) Characterization and beneficiation of Anka chromite ore using magnetic separation process. J Miner Mater Charact Eng 6(2):143-150

Abudaia JA, Sulyman MO, Elazaby KY, Ben-Ali SM (2013) Adsorption of $\mathrm{Pb}$ (II) and $\mathrm{Cu}$ (II) from aqueous solution onto activated carbon prepared from dates stones. Int J Environ Sci Develop 2:191-195

Abukhadra MR, Seliem MK, Mohameda EA, Selim AQ, Mahmoud MH (2015) Application of quadratic polynomial model for the uptake of iron from aqueous solutions by natural and modified Egyptian bentonite. Am J Appl Chem 3:179-183

Akbal F (2005) Photocatalytic degradation of organic dyes in the presence of titanium dioxide under UV and solar light: effect of operational parameters. Environ Progress 24:317-322

Alalm MG, Tawfik A, Ookawara S (2015) Comparison of solar $\mathrm{TiO}_{2}$ photocatalysis and solar photo-Fenton for treatment of pesticides industry wastewater: operational conditions, kinetics, and costs. J Water Process Eng 8:55-63

Bahmani P, Maleki A, Ghahramani E, Rashidi A (2013) Decolorization of the dye reactive black 5 using Fenton oxidation. African J Biotechn 12(26): 15-41

Bandala ER, Peláez MA, García-López AJ, Salgado MdJ, Moeller G (2006) Photocatalytic decolourisation of synthetic and real textile wastewater containing benzidine-based azo dyes. Chem Eng Processin Process Intensif 47(2):169-176

Behnajady MA, Modirshahla N, Hamzavi R (2006) Kinetic study on photocatalytic degradation of $\mathrm{CI}$ acid yellow 23 by $\mathrm{ZnO}$ photocatalyst. J Hazard Mater B 133:226-232

Bubacz K, Choina J, Dolat D, Morawski AW (2010) Methylene blue and phenol photocatalytic degradation on nanoparticles of anatase $\mathrm{TiO}_{2}$. Polish J Environ Stud 19:685-691

Durrani SK, Hussain SZ, Saeed K, Khan Y, Arif M, Ahmed N (2012) Hydrothermal synthesis and characterization of nano sized transition metal chromite spinels. Turk J Chem 36:111-120

Ercan O, Deniz S, Yetimoglu EK, Aydin A (2015) Degradation of reactive dyes using advanced oxidation method. Clean-soil, air. Water 43(7):1031-1036

Feng J, Hu X, Yue PL, Zhu HY, Lu GQ (2003) Discoloration and mineralization of reactive red HE-3B by heterogeneous photoFenton reaction. J Water Res 37:3776-3784

Galindo C, Jacques P, Kalt A (2001) Photooxidation of the phenylazonaphthol $\mathrm{AO} 20$ on $\mathrm{TiO}_{2}$ : kinetic and mechanistic investigations. Chemosphere 45:997-1005

Gogate PR, Sivakumar M, Pandit AB (2004) Destruction of Rhodamine B using novel sonochemical reactor with capacity of 7.51. Sep Purif Technol 34:13-24

Gupta VK, Mohan D, Saini VK (2006) Studies on the interaction of some azo dyes (naphthol red-J and direct orange) with nontronite mineral. J Colloid Interface Sci 298:79-86

Herney-Ramirez J, Lampinen M, Vicente MA, Costa CA, Madeira LM (2008) Experimental design to optimize the oxidation of orange II dye solution using a clay-based fenton-like catalyst. J Eng Chem Res 47:284-294 
Herrmann JM (1999) Heterogeneous photocatalysis: fundamentals and applications to the removal of various types of aqueous pollutants. Catal Today 53:115-129

Huang YH, Huang YF, Chang PS, Chen CY (2008) Comparative Study of oxidation of dye-reactive black B by different advanced oxidation processes: Fenton, electro-Fenton and photo-Fenton. J Hazard Mater 154:655-662

Ibrahim MB, Sani S (2010) Comparative isotherms studies on adsorptive removal of Congo red from wastewater by watermelon rinds and neem-tree leaves. Open J Phys Chem 4:139-146

Ineson PR (1989) Introduction to Practical Ore Microscopy. London: Longman. Wiley, New York. ISBN: 0582301408

Lucas MS, Dias AA, Sampaio A, Amaral C, Peres JA (2007) Degradation of a textile reactive Azo dye by a combined chemical biological process: Fenton reagent-yeast. J Water Res 41:1103-1109

Moroz T, Razvorotneva L, Grigorieva T, Mazurov M, Arkhipenko D, Prugov V (2001) Formation of spinel from hydrotalcite-like minerals and destruction of chromite implanted by inorganic salts. Appl Clay Sci 18:29-36

Muruganandham M, Swaminathan M (2004) Decolourisation of reactive orange 4 by Fenton and photo-Fenton oxidation technology. Dyes Pigm 63:315-321

Ng CM, Chen P-C, Sivakumar M (2012) Hydrothermal crystallization of titania on silver nucleation sites for the synthesis of visible light nano-photocatalysts-enhanced photoactivity using Rhodamine 6G. Appl Catal A 433-434:75-80

Noorjahan M, Durga Kumari V, Subrahmanyam M, Panda L (2005) Immobilized $\mathrm{Fe}(\mathrm{III})-\mathrm{HY}$ : an efficient and stable photo-Fenton catalyst. Appl Catal B 57:291-298

Panda D, Sivakumar M (2017) Recent advancements in the sonophotocatalysis (SPC) and doped-sonophotocatalysis (DSPC) for the treatment of recalcitrant hazardous organic water pollutants. Ultrason Sonochem 36:481-496

Reza KM, Kurny ASW, Gulshan F (2015) Parameters affecting the photocatalytic degradation of dyes using $\mathrm{TiO}_{2}$ : a review. Appl Water Sci. https://doi.org/10.1007/s13201-015-0367-y

Robinson T, McMullan G, Marchant R, Nigam P (2001) Remediation of dyes in textile effluent: a critical review on current treatment technologies with a proposed alternative. Biores Technol 77:247-255

Rodrigues CSD, Madeira LM, Boaventura RAR (2009) Optimization of the azo dye procine red H-EXL degradation by Fenton's reagent using experimental design. J Hazard Mat 164:987-994

Santulli AC, Feygenson M, Camino FE, Aronson M, Wong SS (2011) Synthesis and characterization of one-dimensional $\mathrm{Cr}_{2} \mathrm{O}_{3}$ nanostructures. Chem Mater 23:1000-1008

Seliem MK, Komarneni S, Abukhadra MR (2016) Phosphate removal from solution by composite of MCM-41 silica with rice husk: kinetic and equilibrium studies. Micropo Mesopor Mater J 224:51-57

Shaban M, Abukhadra MR, Hamda A, Amin RR, Abdel Khalek A (2017a) Photocatalytic removal of Congo red dye using MCM$48 / \mathrm{Ni}_{2} \mathrm{O}_{3}$ composite synthesized based on silica gel extracted from rice husk ash; fabrication and application. J Environ Manage 204:189-199

Shaban M, AbuKhadra MR, Shahien MG, Ibrahim SS (2017b) Novel bentonite/zeolite-NaP composite efficiently removes methylene blue and Congo red dyes. Environ Chem lett. https://doi.org/10. 1007/s10311-017-0658-7
Shaban M, Abukhadra MR, Shahien MG, Khan AAP (2017c) Upgraded modified forms of bituminous coal for the removal of safranin-T dye from aqueous solution. Environ Sci Pollut Res 24:18135-18151

Shaban M, Hassouna MEM, Nasief FM, AbuKhadra MR (2017d) Adsorption properties of kaolinite based nanocomposites for $\mathrm{Fe}$ and Mn pollutants from aqueous solutions and raw ground water. Environ Sci Pollut Res, Kinetics and Equilibrium Studies. https://doi.org/10.1007/s11356-017-9942-0

Singh S, Singh PK, Mahalingam HA (2015) Novel and effective strewn polymer-supported titanium dioxide photocatalyst for environmental remediation. J Mater Environ Sci 6(2):349-358

Sivakumar M, Pandit AB (2001) Ultrasound enhanced degradation of Rhodamine B: optimization with power density. Ultrason Sonochem 8:233-240

Sivakumar M, Pandit AB (2002) Wastewater treatment: a novel energy efficient hydrodynamic cavitational technique. Ultrason Sonochem 9:123-131

Sivakumar M, Iida Y, Yasui K, Tuziuti T (2004) Preparation of nano sized $\mathrm{TiO}_{2}$ supported on activated alumina by a sonochemical method: observation of an increased photocatalytic decolourisation efficiency. Res Chem Intermed 30:785-792

Sivakumar M, Towata A, Yasui K, Tuziuti T, Kozuka T, Iida Y (2010) Dependence of sonochemical parameters on the platinization of rutile titania-An observation of a pronounced increase in photocatalytic efficiencies. $\mathrm{J}$ Ult Sonochem 17(3):621-627

Sivakumar D, Shankar D, Vijaya Prathima AJR, Valarmathi M (2013) Constructed wetlands treatment of textile industry wastewater using aquatic macrophytes. Int J Environ Sci 3(4):1223-1232

Sun JH, Sun SP, Sun JY, Sun RX, Qiao LP, Guo HQ, Fan MH (2007) Degradation of azo dye acid black 1 using low concentration iron of Fenton process facilitated by ultrasonic irradiation. J Ult Sonochem 14:761-766

Sun SP, Li CJ, Sun JH, Shi SH, Fan MH, Zhou Q (2009) Decolorization of an azo dye orange $G$ in aqueous solution by fenton oxidation process: effect of system parameters and kinetic study. J Hazard Mater 161:1052-1057

Sun D, Zhang Z, Wang M, Wu Y (2013) Adsorption of reactive dyes on activated carbon developed from Enteromorpha prolifera. Am J Anal Chem 4:17-26

Torrades F, Hortal JAG, Nunez L (2008) Fenton and photo-Fenton oxidation of a model mixture of dyes-overall kinetic analysis. Coloration Technol 124:370-374

Ucbas Y, Bozkurt V, Bilir K, Ipek H (2014) Concentration of chromite by means of magnetic carrier using sodium oleate and other reagents. Physicochem Probl Miner Process 50(2):767-782

Wang N, Li J, Zhu L, Dong Y, Tang H (2008) Highly photocatalytic activity of metallic hydroxide/titanium dioxide nanoparticles prepared via a modified wet precipitation process. J Photochem Photobiol A 198:282-287

Yusuf M, Elfghi FM, Mallak SK (2015) Kinetic studies of safranin-O removal from aqueous solutions using pineapple p. Iranica $\mathbf{J}$ Energy Environ 6(3):173-180

\section{Publisher's Note}

Springer Nature remains neutral with regard to jurisdictional claims in published maps and institutional affiliations. 